\title{
The silver-oxygen system in catalysis: new insights by near ambient pressure X-ray photoelectron spectroscopy $\dagger$
}

\author{
Tulio C. R. Rocha, ${ }^{* a}$ Andreas Oestereich, ${ }^{a}$ Demid V. Demidov, ${ }^{a b}$ \\ Michael Hävecker, $\ddagger^{a}$ Spiros Zafeiratos, ${ }^{c}$ Gisela Weinberg, ${ }^{a}$ Valerii I. Bukhtiyarov, ${ }^{b}$ \\ Axel Knop-Gericke ${ }^{a}$ and Robert Schlögl ${ }^{a}$
}

\author{
Received 8th February 2012, Accepted 10th February 2012 \\ DOI: $10.1039 / \mathrm{c} 2 \mathrm{cp} 22472 \mathrm{k}$
}

We addressed the interaction of oxygen with silver by synchrotron based near ambient pressure $\mathrm{X}$-ray photoelectron spectroscopy at temperatures relevant for industrial oxidation reactions performed with silver catalysts. For silver single crystals, polycrystalline foils and powders in equilibrium with gas phase $\mathrm{O}_{2}$, we observed the dynamics of the formation of five different atomic oxygen species with relative abundances depending on the temperature and time. Correlation of their formation kinetics with spectroscopic features and thermal stability indicates that these are distinct species with different electronic structures, which might relate to the different roles of silver in oxidation reactions.

\section{Introduction}

The oxygen interaction with silver has attracted great attention in the past years because silver based catalysts are used in two important large scale processes in the chemical industry, namely ethylene epoxidation ${ }^{1}$ and methanol oxidation. ${ }^{2}$ These reactions produce highly valuable feedstock chemicals that are used in many applications. Apart from the economic driving force, basic scientific knowledge is also pursued because silver can be regarded as a model system to understand selective oxidations. The epoxidation reaction is catalyzed by silver in its metallic state without bulk oxide formation and this is one of the simplest examples of a kinetically controlled selective oxidation, where ethylene oxide can be obtained as the main product although carbon dioxide is thermodynamically more favorable.

Since the early 1960's different approaches have been used to address the oxygen-silver interaction. Initially, coverages, heats of adsorption and adsorption/desorption kinetics have

${ }^{a}$ Fritz-Haber-Institut der Max-Planck-Gesellschaft, Department of Inorganic Chemistry, Faradayweg 4-6, 14195, Berlin, Germany. E-mail: tulio@fhi-berlin.mpg.de; Fax: + 49308413 4676,

Tel: +493084134421

${ }^{b}$ Boreskov Institute of Catalysis, pr. Lavrentieva 5, Novosibirsk, 630090, Russia

${ }^{c}$ Laboratoire LMSPC UMR7515 CNRS Univ. Strasbourg,

F-67087 Strasbourg cedex 2, France

$\dagger$ Electronic supplementary information (ESI) available: Additional $\mathrm{O} 1 \mathrm{~s}$ spectra. SEM characterization of $\mathrm{Ag}$ foil with silicon contamination. The influence of $\mathrm{Cl}$ on the oxygen species on silver. Details about the correlation of $\mathrm{O}$ species with $\mathrm{Ag}^{+}$amounts. Valence band spectra with different energies. See DOI: $10.1039 / \mathrm{c} 2 \mathrm{cp} 22472 \mathrm{k}$

$\ddagger$ Present address: Helmholtz-Zentrum Berlin/BESSY II, Dept. Solar Energy Research, Albert-Einstein-Str. 15, 12489 Berlin, Germany. been measured for real catalysts and model systems. ${ }^{3-6}$ Later on, with spread of ultra high vacuum technology, oxygen adsorption on single crystals and polycrystalline surfaces were studied by a full range of surface science techniques including low energy electron diffraction, ${ }^{7}$ electron energy loss spectroscopy, ${ }^{8}$ Auger spectroscopy, ultraviolet ${ }^{9,10}$ and X-ray photoelectron spectroscopy. ${ }^{11,12}$ These studies have been mainly devoted to elucidating the atomic and electronic structure of oxygen covered silver surfaces, usually prepared by low oxygen doses (1-10 ${ }^{2}$ Langmuir) using different sources of oxygen. A wealth of information was obtained by this approach. A clear description of atomic oxygen as single species was derived with all the attributes of spectroscopy and chemical reaction. ${ }^{13}$ Based on this knowledge, reaction models were proposed for both ethylene ${ }^{14,15}$ and methanol oxidation reactions. ${ }^{16}$ Later, Schlögl and co-workers devoted special attention to the interaction of oxygen with silver at high temperatures, which would be more representative of real catalysts under methanol oxidation conditions. ${ }^{17-27}$ In contrast to the static description obtained by the classical surface science approach, a very dynamic picture emerged from this series of studies with a strong interplay between oxygen incorporation in the sub-surface and bulk with structural and morphological changes in the silver, which ultimately modifies the oxygen species present at the surface. Systematic theoretical studies based on density function theory calculations were performed by the group of Scheffler. ${ }^{28-31}$ The energetics and the electronic structure of atomic oxygen on silver at different geometries (surface, subsurface, bulk and combinations) and coverages were obtained. Moreover, phase diagrams were determined by taking into account the effect of temperature and pressure through the oxygen chemical potential. With the development of modern 
in situ spectroscopic techniques the interest in this system was renewed with the possibility of testing the proposed models by direct correlation of reactivity data with surface species measured under working conditions. ${ }^{32,33}$

The newly developed near ambient pressure version of the in situ X-ray photoemission spectroscopy (XPS) technique ${ }^{34}$ provides a unique opportunity to characterize the silveroxygen interaction under pressures and temperatures for which the oxygen chemical potential is high enough to sustain both surface adsorption and the morphological/structural transformations in the solid. The main purpose of this paper is to present further evidences for the dynamic nature of oxygen species on silver in equilibrium with gas phase oxygen in the mbar range at catalytically relevant temperatures. Complementary, our aim is also to provide a common framework for the identification, nomenclature and characterization of oxygen species on silver as observed by XPS for different silver materials at two temperature ranges $150-230{ }^{\circ} \mathrm{C}$ and 450-600 ${ }^{\circ} \mathrm{C}$, which are relevant for ethylene epoxidation and methanol oxidation, respectively. This is an important step toward the identification of active species involved in both oxidation reactions on silver catalysts and elucidation of reaction mechanisms, which will be the target of future publications.

\section{Experimental}

Different silver materials were used in this work. Silver foil with $0.25 \mathrm{~mm}$ thickness and $99.997 \%$ purity was purchased from Goodfellow. Silver powder with nominal particle size of $45 \mu \mathrm{m}$ and $99.95 \%$ purity was purchased from Sigma-Aldrich (327107). Silver single crystals $\mathrm{Ag}(110)$ (rectangular $7 \times 7 \times 2 \mathrm{~mm}$ ) and $\operatorname{Ag}(111)($ disk $7 \times 2 \mathrm{~mm})$ were polished with an accuracy of $0.5^{\circ}$ before the experiments.

The single crystals or foils were cleaned by repeating cycles of Ar sputtering $\left(5 \times 10^{-5}\right.$ mbar Ar, $1.5 \mathrm{kV}$ acceleration voltage, $20 \mathrm{~mA}$ emission current) for $30 \mathrm{~min}$ and annealing at $400{ }^{\circ} \mathrm{C}$ for $3 \mathrm{~min}$ in UHV. This procedure was repeated typically 5-10 times until carbon, sulfur or oxygen was no longer observed on the surface in UHV. However, as it will be discussed in the text, after longer $\mathrm{O}_{2}$ exposures at elevated temperatures some impurities appeared on the surface. The silver powder was used as supplied without any cleaning procedure.

In situ XPS experiments were performed using the near ambient pressure endstation of the ISISS beamline at the synchrotron radiation facility BESSY II of the Helmholtz Zentrum Berlin. Details about the system can be found at elsewhere. ${ }^{35}$ Briefly, the silver samples were mounted inside the reaction chamber $1.3 \mathrm{~mm}$ away from the first aperture of the differentially pumped stages of the electrostatic lens system that is connected to a hemispherical electron analyser. The samples were fixed in a sapphire holder allowing the heating from the backside by an infrared laser (CW $808 \mathrm{~nm}$ ). A steel plate was used as infrared absorber and the temperature was measured by a K-type thermocouple fixed on the sample surface by a steel plate lid. The silver powder was measured in the form of pellets. Typically $50 \mathrm{mg}$ of the powders was gently pressed with $20 \mathrm{~kg}$ for $1 \mathrm{~min}$ forming $8 \mathrm{~mm}$ diameter pellets with approximately $0.5 \mathrm{~mm}$ thickness. The $\mathrm{O}_{2}$ flow to the chamber was kept constant by a mass flow controller and the total pressure was regulated by changing the outlet flow, using an automatic valve. A differentially pumped quadrupole mass spectrometer was connected through a leak valve and the gas phase composition was monitored by on-line mass spectrometry during the experiments.

The tunability of the synchrotron source was exploited to select appropriate photon energies in order to measure corelevel spectra for all the elements (oxygen, silver, carbon) with photoelectrons with the same kinetic energy $(220 \mathrm{eV})$. This is important to assure surface sensitivity with the same information depth for all elements. Moreover, it facilitates the quantification since the transmission of the photoelectrons in the lens system and the scattering in the gas phase are the same for all elements. At $780 \mathrm{eV}$ and with a spectrometer pass energy of $10 \mathrm{eV}$, at which the $\mathrm{O} 1 \mathrm{~s}$ spectra were measured, the overall instrumental resolution is $0.4 \mathrm{eV}$ (determined by gas phase measurements) and typical photon flux is in the order of $1.2 \times 10^{11}$ photons $\mathrm{s}^{-1} / 0.1 \mathrm{~A}$. No visible effect of beam damage was present for $\mathrm{Ag}$ samples exposed to $\mathrm{O}_{2}$ at different temperatures as evidenced by the comparison of spectra at different spots on the same sample.

The binding energy scale for all the measurements were calibrated with respect to the Fermi edge, which was measured after each core-level and valence band spectra using the same photon energy. The precision of our energy calibration was estimated to be $30 \mathrm{meV}$ by measuring the fluctuations of the Ag $3 d^{5 / 2}$ peak position for clean samples after the Fermi edge correction. The spectra shown in the figures are intensity offset for clarity.

Curve fitting was performed with the CasaXPS software (Neil Farley www.casaxps.com). For O1s, a mixed Gaussian/ Lorentzian $(70 \% / 30 \%)$ line shape was used in combination with a linear background. A total of six components were used with the peak position and width constrained at different ranges for each component; the values are presented in Table S1 in the ESI. $\dagger$ For the Ag3d, the best description of the line shape was a Doniach-Sunjic curve convoluted with a Gaussian function. The asymmetry parameter was fixed as 0.03 and the Shirley background was offset to accommodate the asymmetric tail. The Gaussian broadening and FWHM were determined for the clean silver and kept constant. Elemental atomic concentrations were obtained by dividing the areas resulted from fitting by the incident photon flux and the atomic photoionization cross sections calculated by Yeh and Lindau ${ }^{36}$ for the appropriate energies. It is worth mentioning that this approach is not expected to give accurate absolute elemental composition results, but relative values so that different measurements can be compared.

Fitting of O1s spectra for silver is not straightforward and care must be taken. In general, multiple components are likely to be present with $\mathrm{BE}$ separations which can be equal or smaller than half of the FWHM, even using monochromatic synchrotron radiation. In such conditions, the parameters for adjacent Gaussian components obtained from the fitting procedure might suffer from strong correlation depending on the signal-to-noise ratio. For instance, a decrease in the area of one component might be compensated by an increase in the FWHM 
of the adjacent peak giving the same goodness-of-fit. To minimize these problems, the energy scale must be carefully calibrated and reasonable constraints must be applied for the BE and FWHM, based on reference measurements. However, the parameters must not be fixed but constrained to a small interval around a reference value, since BE variations caused by physical reasons are possible, like modifications in the local binding arrangement, neighboring, relaxation mechanism, etc. The fitting model used in this work, namely the number of oxygen species, its BE and FWHM, was obtained by choosing the best set of parameters that could describe not a single spectrum but dozens of O1s spectra measured under different conditions. More details about the fitting procedure and additional examples are given in the ESI $\dagger$ (Fig. S2).

\section{Results}

\section{Carbon removal and atomic oxygen species on silver}

Under $0.25 \mathrm{mbar}$ of $\mathrm{O}_{2}$ and below $130{ }^{\circ} \mathrm{C}$, the silver surface is covered with carbonates $\left(\mathrm{Ag}_{2} \mathrm{CO}_{3}\right)$ and hydrocarbons arising either from the residual gases inside the chamber or from contact with ambient (for the powders that could not be cleaned by Ar sputtering). As the temperature is raised to 130-150 ${ }^{\circ} \mathrm{C}$ under an $\mathrm{O}_{2}$ atmosphere, firstly the hydrocarbons and then the carbonates gradually vanish until the silver surface is finally free of carbon after $10 \mathrm{~min}$ (See ESI $\dagger, \mathrm{S} 1$ ). For all results presented henceforth, carbon is absent from the silver surfaces, as always confirmed by $\mathrm{C} 1 \mathrm{~s}$ spectra. This absence of carbon is very important for trustworthy assignment of features in the $\mathrm{O} 1 \mathrm{~s}$ as atomic oxygen species on silver.

Finally, immediately after carbon removal, a sharp peak appeared at $528.4 \mathrm{eV}$ with a slightly asymmetric tail to higher BE. Analogous behavior was observed for single crystals, foils and powders with different grain sizes, but the peak BE varied in the range $528.2-528.5 \mathrm{eV}$ with full width at half maximum (FWHM) of $0.85-1.0 \mathrm{eV}$. This feature was previously observed in several UHV experiments for single crystals and polycrystalline foils. ${ }^{11,32,37-39}$ Although different names have been used, most authors describe it as an oxidic species being associated with reconstructions on the single crystal surfaces. Here we use the label, $\mathrm{O} \alpha_{1}$ in connection with our previous works and the traditional thermal desorption notation. ${ }^{17-25,27}$

\section{Dynamics of oxygen species at $150-230{ }^{\circ} \mathrm{C}$}

Fig. 1(a) shows O1s spectra measured under $0.25 \mathrm{mbar}_{2}$ at different temperatures for $\operatorname{Ag}(110)$. The temperature was raised by $5{ }^{\circ} \mathrm{C} \mathrm{min}^{-1}$ and held constant at 150,180, 200 and $230{ }^{\circ} \mathrm{C}$ for $30 \mathrm{~min}$, for spectra acquisition. Initially, fast scans were acquired and when changes were no longer observed in a time scale of $10 \mathrm{~min}$, a set of core-levels for different elements was measured (carbon, oxygen, silver, chlorine, silicon), for which the O1s signals are displayed in Fig. 1(a). After a few minutes at $150{ }^{\circ} \mathrm{C}$, the initial tail in the $\mathrm{O} \alpha_{1}$ component (similar to the bottom spectra of Fig. S1, ESI $\dagger$ ) developed into a well defined shoulder around $529.2 \mathrm{eV}$ and an additional peak at $530.2 \mathrm{eV}$, as shown in Fig. 1(a). As the temperature was increased, while the shoulder remained nearly constant, the peak initially around $530.2 \mathrm{eV}$ increased and shifted to high BE.
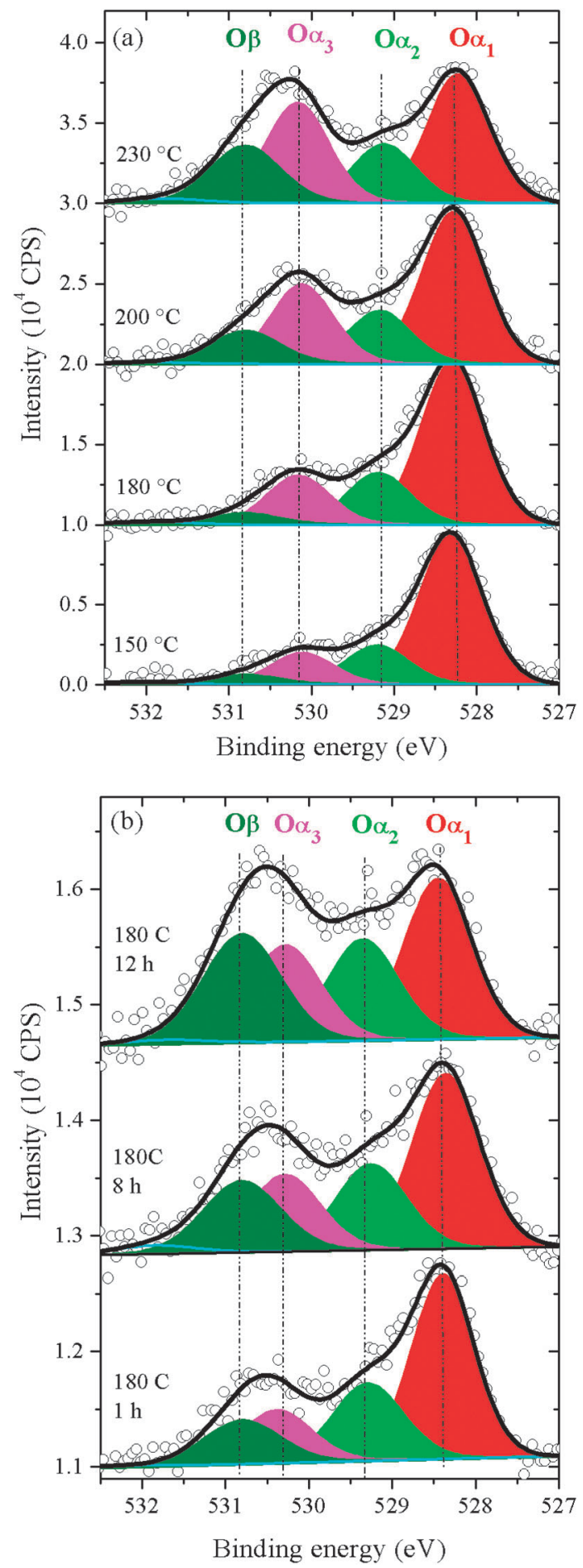

Fig. 1 Ols spectra following the formation dynamics of low temperature oxygen species on silver. (a) $\mathrm{Ag}(110)$ under $0.25 \mathrm{mbar}_{2}$ at different temperatures. (b) Silver powder with $45 \mathrm{~mm}$ particle size at $180{ }^{\circ} \mathrm{C}$ at different times.

Since no carbon or other oxygen-containing impurities were present, these new features can be assigned as additional oxygen species on silver, however a fitting procedure is necessary.

The fitting of the $\mathrm{O} 1 \mathrm{~s}$ spectra for $\mathrm{Ag}(110)$ at $150{ }^{\circ} \mathrm{C}$ (Fig. 1(a)) results in essentially three components. The low $\mathrm{BE}$ component 
at $528.2 \mathrm{eV}$ is assigned to the same species $\mathrm{O} \alpha_{1}$ previously described. Oxygen species in the range of $530.0-530.6 \mathrm{eV}$ have been reported many times in the literature for silver. ${ }^{12,25,32,38}$ This species is labeled $\mathrm{O} \alpha_{3}$ and assigned as atomic oxygen adsorbed at the silver surface.

The middle component at $529.2 \mathrm{eV}$, named $\mathrm{O} \alpha_{2}$, is more scarcely described in the literature. A feature in this energy range was measured for silver single crystals after high temperature treatments at 1 bar, ${ }^{20,25}$ being associated to the highly stable $\mathrm{O} \gamma$ species previously observed in thermal desorption experiments. Species on this range were also observed for $\operatorname{Ag}(001)$ single crystals exposed to $\mathrm{O}_{2}$ below room temperature ${ }^{38}$ and silver foils exposed to microwave discharges in the presence of $\mathrm{O}_{2}$ at room temperature. ${ }^{40,41}$ Both species $\mathrm{O} \alpha_{2}$ and $\mathrm{O} \alpha_{3}$ have FHWM around $1 \mathrm{eV}$ in the same range as $\mathrm{O} \alpha_{1}$. For an overview of all the $\mathrm{O}$ species described in this paper we refer the reader to Table 1 in the discussion section.

As the temperature is further increased up to $230{ }^{\circ} \mathrm{C}$, the feature at $530.2 \mathrm{eV}$ shifts to high binding energy and becomes relatively more asymmetric and broader. To fit this line shape, an additional component around $530.8 \mathrm{eV}$ with $1.1 \mathrm{eV}$ FWHM needs to be introduced. As can be seen in Fig. 1(a), its appearance is delayed relative to the $\mathrm{O} \alpha_{1,2,3}$, but it increases at a higher rate as a function of temperature. Based on that, we associate this component to an oxygen species incorporated in the sub-surface region and label it $O \beta$ in connection with the bulk diluted oxygen species previously characterized by TDS. ${ }^{17-25,27}$ However, since XPS is not bulk sensitive, this $\mathrm{O} \beta$ species is better described as oxygen in octahedral sites below the silver surface in this case. These assignments are corroborated by the high temperature experiments and will be more extensively discussed in comparison to the literature in the discussion section.

Interestingly, a very similar evolution of the oxygen species can be observed even at a constant temperature but at much longer time scale. Fig. 1(b) shows the O1s spectra as a function of time for the case of a silver powder with $45 \mu \mathrm{m}$ average grain size under $0.25 \mathrm{mbar}$ at $180^{\circ} \mathrm{C}$. It can be seen that using the same set of components with slightly broader peaks than in the case of the single crystal all the spectra can be properly fitted. The fitting show that after $1 \mathrm{~h}$ at $180^{\circ} \mathrm{C}$ the distribution of $\mathrm{O} \alpha_{1,2,3}$ species at the surface of the powder is similar to the single crystal at the same temperature, but there is a higher amount of $O \beta$ relative to the other species. The small decrease of $\mathrm{O} \alpha_{1}$ observed in both cases after higher temperatures or longer exposures is not related to the kinetics of species formation, but to the accumulation of chlorine at the silver surface, as further discussed in the following section.

\section{Dynamics of oxygen species at $500{ }^{\circ} \mathrm{C}$}

At temperatures relevant for methanol oxidation $\left(400-600{ }^{\circ} \mathrm{C}\right)$ the silver-oxygen system shows an enhanced dynamic behavior. Fig. 2(a) presents the O1s spectra for a silver foil at $0.25 \mathrm{mbar}$ $\mathrm{O}_{2}$ initially at $180{ }^{\circ} \mathrm{C}$, which is subsequently heated to $500{ }^{\circ} \mathrm{C}$ for $12 \mathrm{~h}$ and then cooled to $180{ }^{\circ} \mathrm{C}$. The formation of new species is evident even without any fitting procedure by the prominent changes in the line shape and intensity of the $\mathrm{O} 1 \mathrm{~s}$ spectra. The spectrum at $180^{\circ} \mathrm{C}$ shows a very similar distribution of oxygen species as previously observed for single crystal
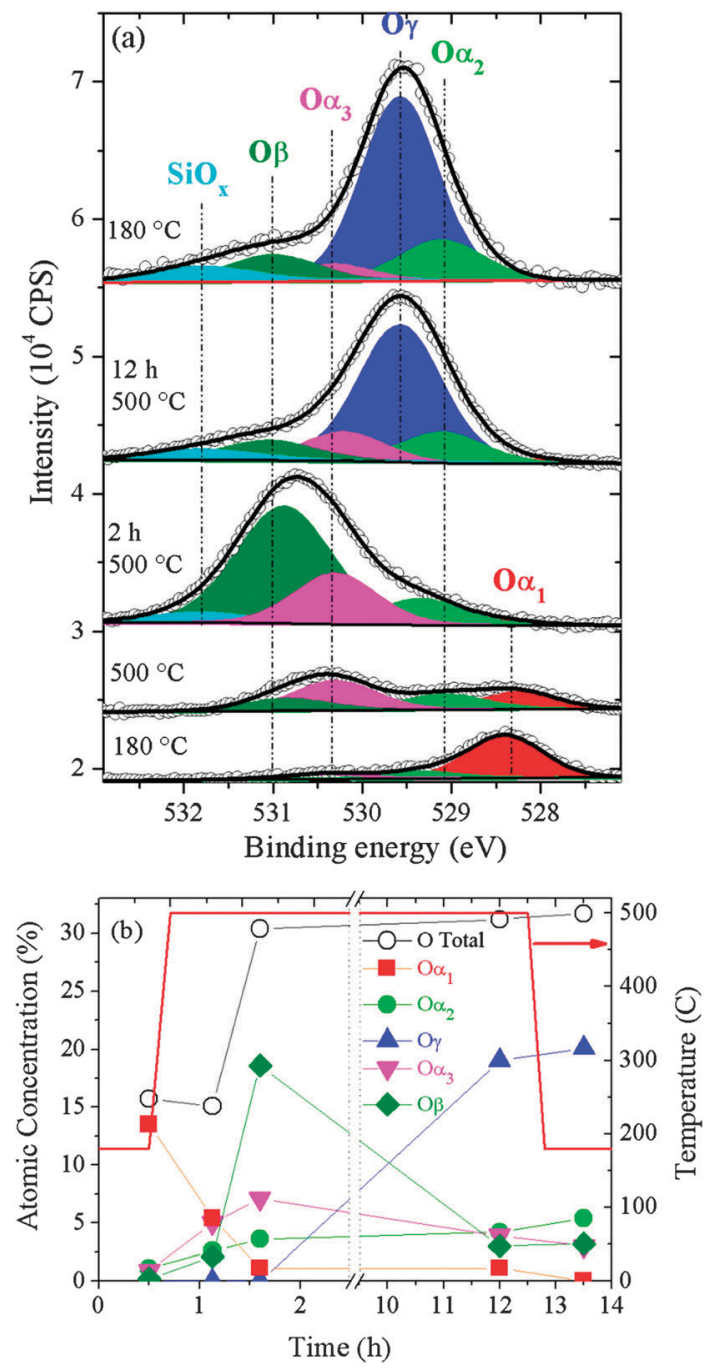

Fig. 2 (a) O1s spectra for silver foil under $0.25 \mathrm{mbar}_{2}$ at different temperatures. (b) Quantitative XPS data showing the evolution of oxygen species at high temperature.

and powder (Fig. 1). However, as the temperature is increased to $500{ }^{\circ} \mathrm{C}, \mathrm{O} \beta$ becomes the most abundant species, while $\mathrm{O} \alpha_{1}$ is significantly reduced. The same relative binding energies are used but the FHWM for all species is a little higher than for the measurements at lower temperatures. Later on, after $2 \mathrm{~h}$ at $500{ }^{\circ} \mathrm{C}$, the total amount of oxygen increases substantially, as seen by the higher O1s overall intensity. At this point, $\mathrm{O} \alpha_{1}$ and $\mathrm{O} \alpha_{2}$ vanish and $\mathrm{O} \beta$ completely dominates the spectrum with $\mathrm{O} \alpha_{3}$ being a minor contribution.

Finally, after $12 \mathrm{~h}$ under $500{ }^{\circ} \mathrm{C}$, it can be seen that $\mathrm{O} \beta$ is strongly reduced and a new peak at $529.5 \mathrm{eV}$ appears. This feature is fitted using two components, the $\mathrm{O} \alpha_{2}$ previously observed at lower temperatures and a new species at $529.6 \mathrm{eV}$, which is assigned to the so-called $\mathrm{O} \gamma$, in connection with highly stable oxygen species observed in TDS experiments after high temperature $\mathrm{O}_{2}$ treatments. ${ }^{27}$ As in the case of $\mathrm{O} \alpha_{3}$ and $\mathrm{O} \beta$, the BE separation between $\mathrm{O} \gamma$ and $\mathrm{O} \alpha_{2}$ is small $(0.5 \mathrm{eV})$ compared to the FWHM $(1.1 \mathrm{eV})$ and errors in the fitted areas are likely to be present if the BE and FHWM are not constrained. The evolution of the oxygen species on silver at high temperatures can be followed quantitatively by plotting the 


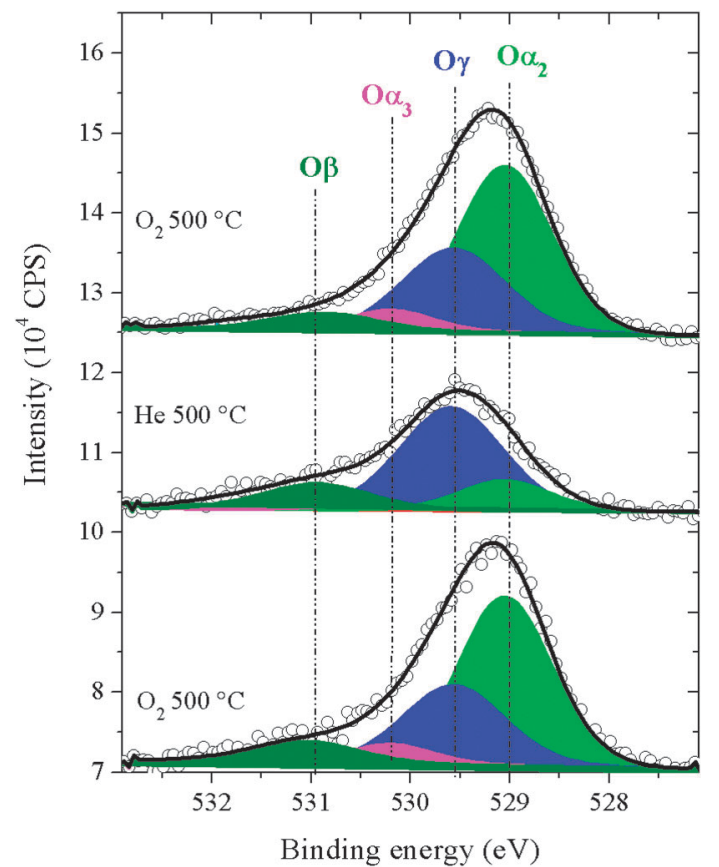

Fig. $3 \mathrm{O} 1 \mathrm{~s}$ spectra for $\mathrm{O} 1 \mathrm{~s}$ spectra for silver foil at $500{ }^{\circ} \mathrm{C}$ under different gas environments.

atomic concentrations obtained by the peak areas as a function of time (Fig. 3). The total amount of oxygen on silver increases by a factor of 2.0 during the first few hours at $500{ }^{\circ} \mathrm{C}$ due to $\mathrm{O} \beta$ formation. Subsequently after $12 \mathrm{~h} \mathrm{O} \gamma$ is formed at the expense of $\mathrm{O} \beta$ but the total amount of oxygen stay nearly unchanged.

To confirm the assignment of the new feature as $\mathrm{O} \gamma$, a new experiment was performed where a silver foil was exposed to $\mathrm{O}_{2}$ at $500{ }^{\circ} \mathrm{C}$ for $3 \mathrm{~h}$ and then the $\mathrm{O}_{2}$ was replaced by $\mathrm{He}$ while the temperature was kept at $500{ }^{\circ} \mathrm{C}$ for $30 \mathrm{~min}$ and afterwards $\mathrm{O}_{2}$ was reintroduced. As can be seen in Fig. 3, the spectrum under $\mathrm{O}_{2}$ shows a peak at $529.3 \mathrm{eV}$, which decreases in intensity, shifts to $529.6 \mathrm{eV}$ and becomes narrower under $\mathrm{He}$, but it is recovered as $\mathrm{O}_{2}$ is reintroduced. The fitting indicates that both $\mathrm{O} \alpha_{2}$ and $\mathrm{O} \alpha_{3}$ decrease considerably under $\mathrm{He}$ while the components assigned as $\mathrm{O} \gamma$, on the other hand, remain nearly constant, confirming its expected high thermal stability.

After the high temperature treatment, when the temperature was decreased back to $180^{\circ} \mathrm{C}$ no changes in the distribution of oxygen species were observed (Fig. 2(a, b)). This invariability indicates that the $\mathrm{O} \gamma$ formation is an irreversible process. The long time scale and irreversibility of the oxygen species evolution at high temperature suggest that solid state dynamics might be also involved. In fact, strong morphological changes are observed on the silver foil after the high temperature $\mathrm{O}_{2}$ treatments. Fig. 4(a) shows a representative SEM image of the fresh silver foil. The foil surface is flat in the micrometre scale with some roughness caused by unidirectional line shaped structures that are formed during the foil fabrication and polishing.

In contrast, after the $12 \mathrm{~h}$ under $0.25 \mathrm{mbar}_{2}$, its surface presented a much richer morphology. As seen in Fig. 4(b) (at the same magnification as Fig. 4(a)), the grain boundaries are clearly visible and in some areas dark and grey stripes are present. This stripe-like contrast is due to the formation of hill and valley structures as observed in Fig. 4(c) which is a magnification of
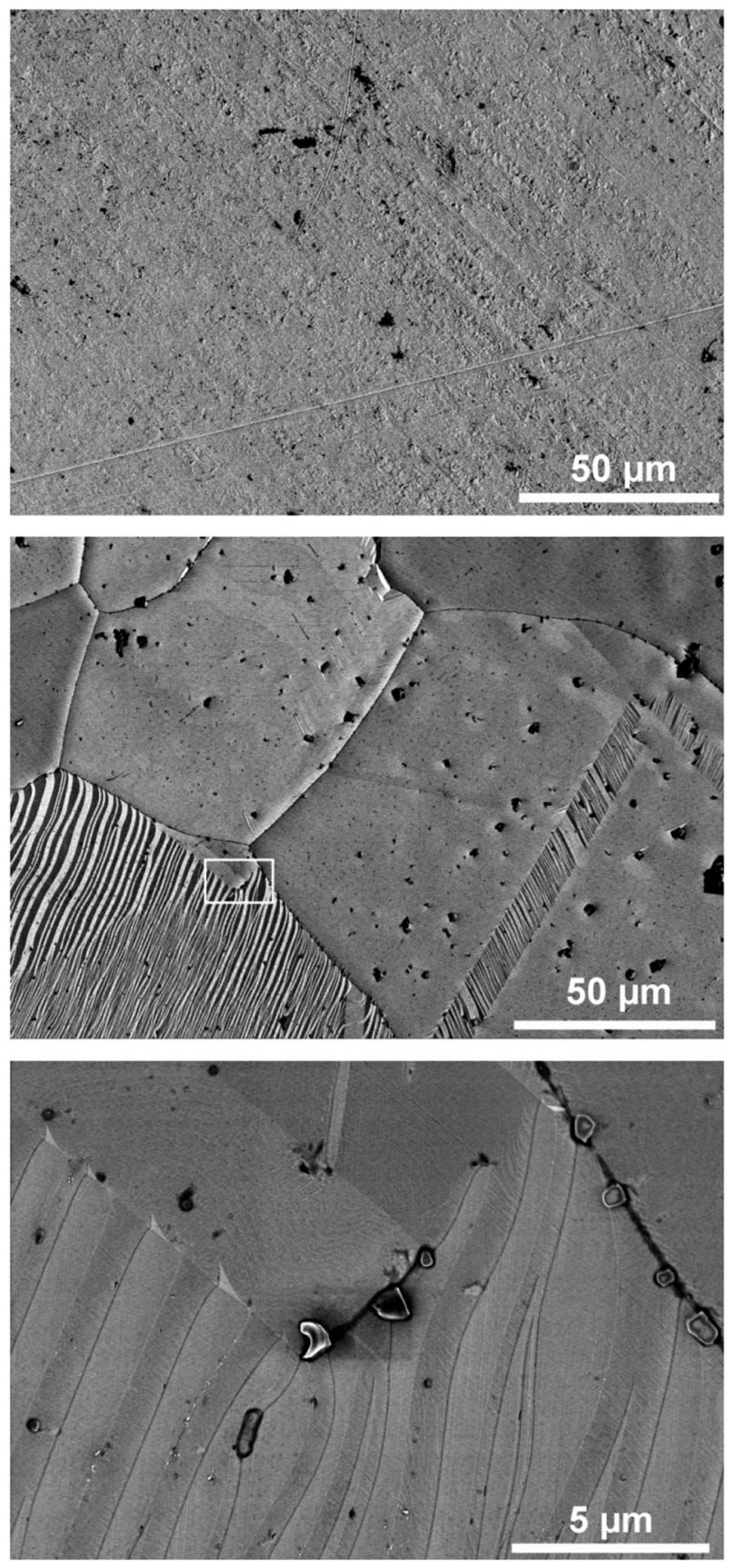

Fig. 4 Morphological changes of $\mathrm{Ag}$ foil under $0.25 \mathrm{mbar}_{2}$ at $500{ }^{\circ} \mathrm{C}$. (a) Fresh foil after various cleaning cycles. (b-c) After exposure to $\mathrm{O}_{2}$ at $500{ }^{\circ} \mathrm{C}$ for $12 \mathrm{~h}$. Image (c) is a magnification of the area marked by a square in (b).

the area marked by a rectangle in Fig. 4(b). This restructuring of the silver surface observed at 0.25 mbar during the XPS measurements is similar to what is reported in the literature for 1 bar treatments. ${ }^{19,21}$

\section{Surface impurities}

One of the goals of this paper is to tackle the dynamics of $\mathrm{O}$ species as the $\mathrm{Ag}$ surface equilibrates with the gas phase atmosphere and temperature in time scales representative for real catalytic systems. This information is very important for 
catalysis and almost not available by traditional surface science methods. However, the price paid for this information is the long time inside the chamber, which results in adsorption/ segregation of additional elements other than $\mathrm{O}$ to the $\mathrm{Ag}$ surface. In contrast to UHV experiments, where surface contamination arise from vapor-pressure driven diffusion of residual impurities from the vacuum chamber to the sample, gas phase transport can play an important role in the case of near ambient pressure XPS. A typical example of gas mediated transport is the nickel/iron contamination for samples in $\mathrm{CO}$ atmospheres, as a result of formation and decomposition of carbonyls. ${ }^{42} \mathrm{~A}$ second source of contamination is the thermal segregation of bulk impurities to the surface, which might also be enhanced by the presence of a gas phase, for example in the case of silver, because of the incorporation of oxygen in the sub-surface and bulk and the increased chemical potential.

In most experiments with single crystals or foils where the samples are cleaned by Ar sputtering, only oxygen is present on the Ag surface (Fig. 1(a), 150 to $200{ }^{\circ} \mathrm{C}$, Fig. 1(b) $2 \mathrm{~h}$, Fig. 2(a) up to $30 \mathrm{~min}$ at $500{ }^{\circ} \mathrm{C}$ and Fig. 3). However, after longer exposures times to oxygen and temperature different contaminants were observed on silver depending on the conditions. The surface of fresh powders and foils contains carbon and sometimes sulfur that disappear after exposure to $\mathrm{O}_{2}$ at temperatures higher than $150{ }^{\circ} \mathrm{C}$. Depending on the sample history and time, chlorine is occasionally present between 150 and $250{ }^{\circ} \mathrm{C}$, while at $500{ }^{\circ} \mathrm{C}$ potassium and silicon are sometimes observed. While potassium does not seem to influence the O1s spectra, considerable changes are observed in the presence of both silicon and chlorine and these cases are worth discussing.

At low temperatures, the presence of residual $\mathrm{OH}$ species was excluded, based on previous investigations which report their $\mathrm{BE}$ in the range of $531.6-532.6 \mathrm{eV} .{ }^{43}$ However, a high binding energy feature between 531.5 and $532.5 \mathrm{eV}$ was occasionally observed for silver foils exposed to $\mathrm{O}_{2}$ at high temperatures, which is not a new atomic oxygen species on silver, but a silicon oxide related feature. Fig. 5 shows spectra for which the silicon oxide contamination is present. As can be seen, the changes in intensity for this O1s feature correlates well with Si2p peak. This contamination is particularly bewildering, because $\mathrm{Si}$ is usually present in a distribution of oxidation states as indicated by the broad peak (1.8 eV FWHM), which is not always the same, causing the corresponding O1s feature to shift (Fig. 5(a)). As shown quantitatively in Fig. 6, both the $\mathrm{O} / \mathrm{Si}$ atomic concentration ratio and the $\mathrm{BE}$ position of the $\mathrm{O} 1 \mathrm{~s} \mathrm{SiO}_{x}$ component are clearly correlated with the $\mathrm{BE}$ position of the $\mathrm{Si}$ $2 p$ peak. Silicon oxide impurities were thermally stable and could be removed only by Ar sputtering. However, our experiments indicate that the presence of silicon oxide impurities does not influence the oxygen adsorption characteristics of silver (coverage and speciation). The absence of surface passivation by silicon oxide is in agreement with the SEM characterization showing the segregation of silicon oxide into isolated particles instead of wetting the silver surface (see ESI $\dagger$, Fig. S3).

It is plausible that silicon contamination is not specific for our system, this impurity creating an O1s signal at $531.5-533 \mathrm{eV}$ might be relevant for other studies in the literature as well. The huge difference in sensitivity factors between silicon and oxygen for XPS analysis based on $\mathrm{Al} / \mathrm{Mg} \mathrm{K} \alpha$ sources might easily
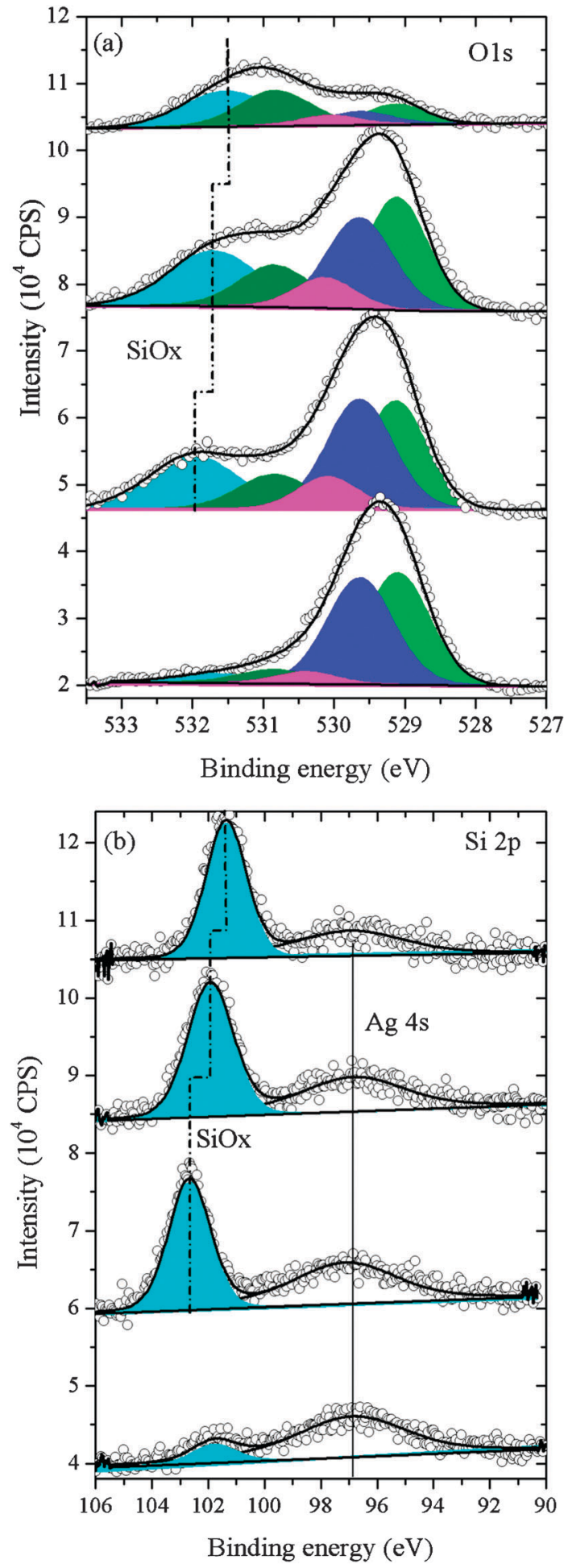

Fig. 5 Silicon contamination in $\mathrm{Ag}$ foils exposed to $0.25 \mathrm{mbar}_{2}$ at $500{ }^{\circ} \mathrm{C}$. (a) $\mathrm{O} 1 \mathrm{~s}$ spectra showing the appearance of an additional $\mathrm{SiO}_{x}$ component between 531.4 and $532.5 \mathrm{eV}$. (b) Corresponding Si2p spectra.

hinder the detection of the Si2p signal while the corresponding O1s feature is still observed (see ESI $\dagger$, Fig. S4). For instance, Bukhtiyarov reported the presence of a residual broad peak in the $\mathrm{O} 1 \mathrm{~s}$ spectra around $532 \mathrm{eV}$ for polycrystalline foils, which does not influence the oxygen adsorption, but it is not removed 


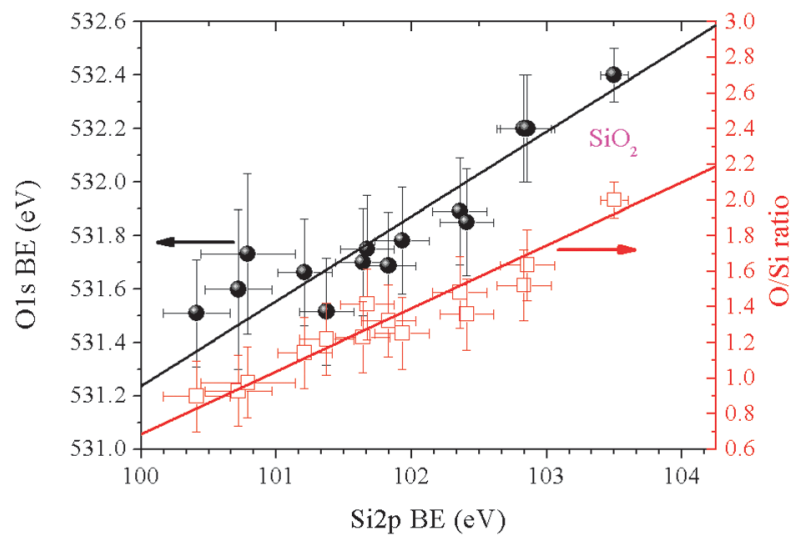

Fig. 6 Correlation of the $\mathrm{Si} 2 \mathrm{p}$ peak position with the $\mathrm{BE}$ of the $\mathrm{SiO}_{x}$ component in the Ols spectra (filled dots) and with the ratio of atomic concentrations of oxygen and silicon (open squares).

even after severe $\mathrm{O}_{2}$ and $\mathrm{H}_{2}$ redox cleaning and flashing in UHV at $600{ }^{\circ} \mathrm{C}$. Similar descriptions of highly stable residual oxygen on silver are also reported by other authors, ${ }^{44}$ which might be well related to silicon oxides. In fact the surface segregation of bulk silicon impurities was observed for $\mathrm{Ag}$ single crystals after high pressure ethylene epoxidation ${ }^{39}$ and methanol oxidation reactions. ${ }^{19}$

The interplay between chlorine and oxygen at silver surface was investigated in more details by ambient pressure XPS and the results will be published elsewhere. Briefly, our experiments indicate that, in contrast to silicon, the presence of chlorine influences not only the oxygen uptake by silver but also the distribution of oxygen species. It has already been proposed in the literature that $\mathrm{Cl}$ preferentially adsorbs at specific sites for oxygen covered silver surface, leading to changes in the distribution of oxygen species. ${ }^{1}$ We observed that the low $\mathrm{BE}$ oxygen species $\left(\mathrm{O} \alpha_{1}\right.$ and $\left.\mathrm{O} \alpha_{2}\right)$ are initially reduced as chlorine accumulates at the surface and only at higher coverage the other species are affected (see ESI $\dagger$, Fig. S5).

\section{The nature of oxygen species}

Another important parameter to characterize the species, apart from the binding energy and kinetics, is the associated formation of $\mathrm{Ag}^{\delta+}$. When no oxygen is present on the silver surface, as for the case of a freshly sputtered $\operatorname{Ag}(110)$ single crystal presented in the top spectra of Fig. 7(a,b) the Ag3d spectra show a peak at $368.15 \mathrm{eV}$ with FWHM of $0.65 \mathrm{eV}$. When $\mathrm{O} \alpha_{1}$ is present on the silver surface, the $\mathrm{Ag} 3 \mathrm{~d}$ line-shape changes and a shoulder at lower binding energies are clearly noticed. The majority of metals display a core-level chemical shift to higher binding energies for higher oxidation state, as predicted by a simple charge potential model. However, in the case of silver, the response of the local electronic structure to the appearance of the core-hole gives rise to an additional factor, usually called relaxation energy, which results in an overall shift to lower binding energies. ${ }^{45}$ Comparison of the line shapes of the Ag3d spectra in Fig. 6 suggests that the amount of $\mathrm{Ag}^{\delta+}$ depends on species present on the surface, as already pointed out qualitatively by other authors. ${ }^{32,40,41}$

A good fitting of the Ag3d can be obtained with the inclusion of a second component with $30 \%$ broader FWHM relative to the metal and a $\mathrm{BE}$ shift between 0.35 and $0.55 \mathrm{eV}$ relative to the $\mathrm{Ag}^{0}$. The quantitative correlation between the $\mathrm{Ag}^{+}$abundance and the different oxygen species is not simple since in most cases a distribution of species is present. To tackle this issue, for each pair of $\mathrm{O} 1 \mathrm{~s} / \mathrm{Ag} 3 \mathrm{~d}$ spectra a linear equation was constructed using the areas of the oxygen components as coefficients for the unknown variables and the $\mathrm{Ag}^{+}$areas as constants. A linear system was then constructed whose solutions gave the correlation between the different

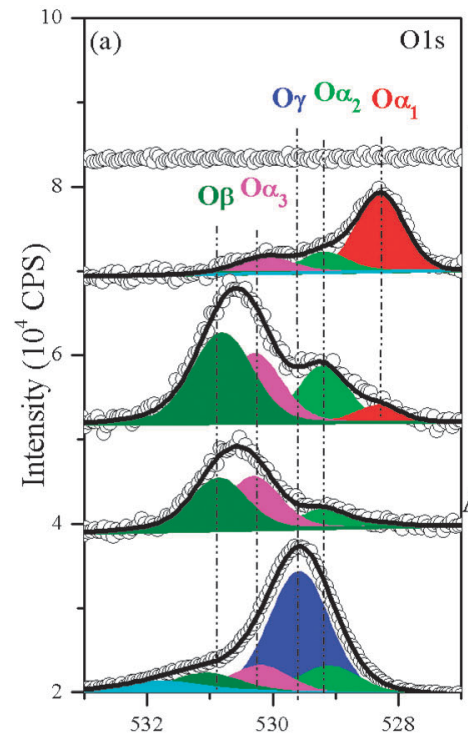

Binding energy (eV)

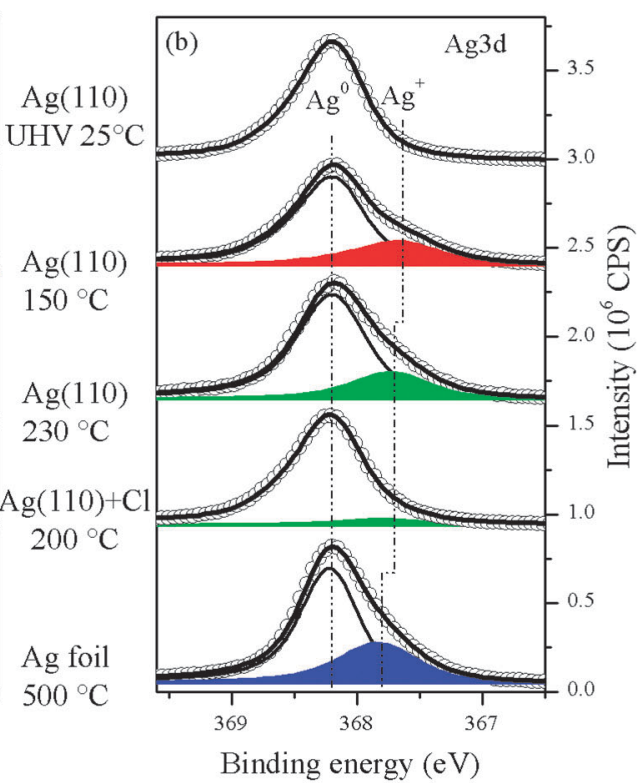

Binding energy (eV)

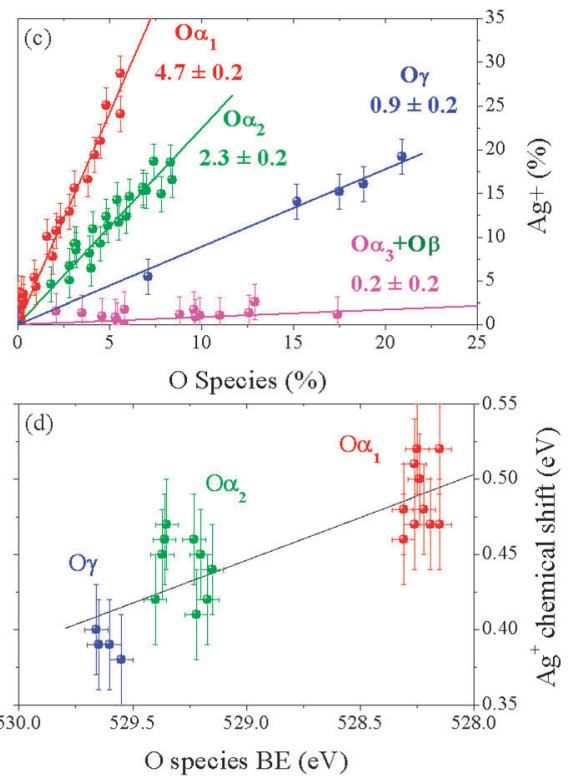

O species BE $(\mathrm{eV})$

Fig. 7 (a, b) Corresponding $\mathrm{O} 1 \mathrm{~s}$ and $\mathrm{Ag} 3 \mathrm{~d}$ spectra showing the changes in the $\mathrm{Ag}^{+}$depending on the oxygen species present on the silver surface. (c) Quantitative correlation of the amount of $\mathrm{Ag}^{+}$related to different oxygen species. (d) Relative $\mathrm{BE}$ for $\mathrm{Ag}^{+}$relative to $\mathrm{Ag}^{0}$ (chemical shift) for different oxygen species. 
oxygen species and $\mathrm{Ag}^{+}$amount (see more details in the ESI $\dagger$ ). The results of this analysis are displayed in Fig. 7(c). $\mathrm{O} \alpha_{1}$ is related to two times more $\mathrm{Ag}^{\delta+}$ than $\mathrm{O} \alpha_{2}$, while the presence of $\mathrm{O} \gamma$ relates to only half of the amount. Interestingly, this analysis indicates that $\mathrm{O} \alpha_{3}$ and $\mathrm{O} \beta$ are related to nearly no $\mathrm{Ag}^{\delta+}$ formation. We have also observed a weak correlation of the $\mathrm{BE}$ position of the $\mathrm{Ag}^{\delta+}$ component with the oxygen species present at the surface, as can be seen at Fig. 7(d). Although considerable fluctuations are present due to variations in the fitting procedure, higher chemical shifts for the $\mathrm{Ag}^{+}$are observed for oxygen species with lower BE. In summary, the quantitative correlation of the $\mathrm{Ag} 3 \mathrm{~d}$ and $\mathrm{O} 1 \mathrm{~s}$ features indicates that the five oxygen species indentified by spectrum fitting are in fact chemically distinct, presenting bonds with different ionic character.

Further evidence for the distinct character of the oxygen species on silver can be obtained by comparing the valence band (VB) features. Fig. 8 shows the O1s spectra and the corresponding VB spectra for selected conditions where one of the species is dominant. All spectra were normalized for better comparison. The oxygen-free silver (bottom spectrum) shows the typical d-band doublet structure between 8 and $4 \mathrm{eV}$ followed by flat and low intensity region from $3.8 \mathrm{eV}$ up to the Fermi edge related to the s-band, in agreement with assignments in the literature based on calculated density of states. ${ }^{46}$ In the presence of $\mathrm{O} \alpha_{1}$ an additional feature appears around $2 \mathrm{eV}$ which is related to the $\mathrm{O} 2 \mathrm{p}$ levels. The assignment of this peak as an oxygen feature was confirmed by measurements with different photon energies, for which the atomic ionization cross section ratio between the $\mathrm{O} 2 \mathrm{p}$ and $\mathrm{Ag} 5 \mathrm{~s}-4 \mathrm{~d}$ increases, and a corresponding enhancement of the peak at $2 \mathrm{eV}$ is observed (see ESI $\dagger$, Fig. S6). In the presence of other oxygen species on the surface the O2p VB level undergoes a similar shift as the O1s core-level, corroborating the assignment of these VB features as related to oxygen species on silver. Systematic theoretical and experimental studies of the electronic structure of $\mathrm{Ag}_{2} \mathrm{O}$ point towards a re-hybridization between the Ag4d and 5s bands allowing the formally closed $4 \mathrm{~d}$ shell to interact in chemical bonding. ${ }^{47,48}$ In general, it is well known that a transition metal oxide presents a considerable
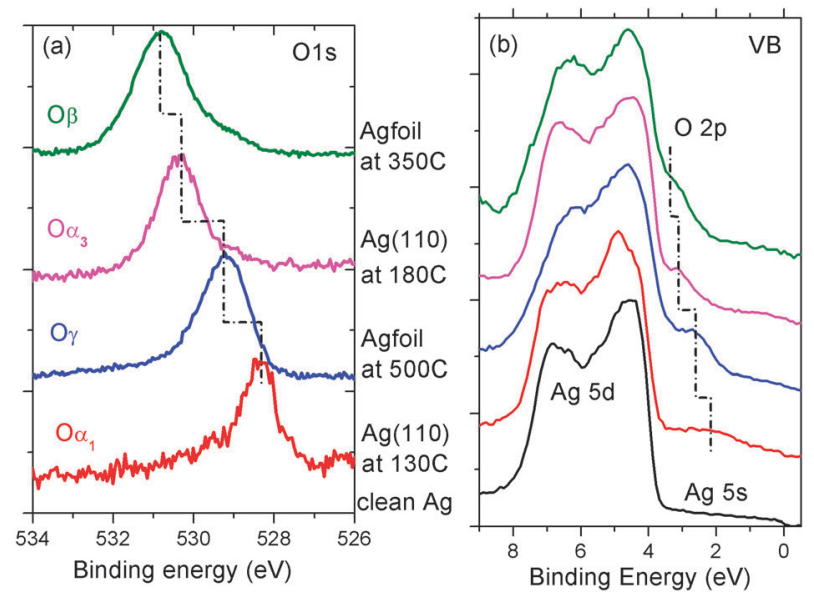

Fig. 8 Comparison of core-level and valence band features for different oxygen species. (a) O1s spectra for selected conditions with different distributions of oxygen species. (b) Corresponding valence band spectra. degree of covalency ${ }^{49}$ In the case of $\mathrm{Ag}$, the low coordination of metal sites, the short bond lengths and the occasional presence of colours associated with the observation of a white line in the $\mathrm{X}$-ray absorption spectra of the $\mathrm{Ag} \mathrm{L}_{3}$ for different $\mathrm{Ag}$ compounds edges have been attributed to an open $d$ shell structure..$^{50}$ In the present case of atomic oxygen interacting with $\mathrm{Ag}$, it is probable that different intermixing between $\mathrm{O} 2 \mathrm{p}$ and $\mathrm{Ag} 4 \mathrm{~d} / 5 \mathrm{~s}$ are present for the different $\mathrm{O}$ species, however further evidences are necessary to address this issue.

\section{Discussion}

The changes in the O1s spectra for a silver single crystal, foil or powder under $0.25 \mathrm{mbar} \mathrm{O}_{2}$ at different temperatures were explained by the formation of five distinct oxygen species, which can be related to species previously described in the literature based on their $\mathrm{BE}$, formation kinetics, temperature stability, $\mathrm{Ag}^{\delta+}$ and valence band features summarized in Table 1.

Table 1 Spectroscopic characteristics of oxygen species on silver

\begin{tabular}{lllll}
\hline Species & $\mathrm{BE} / \mathrm{eV}$ & $\mathrm{FWHM}^{a} / \mathrm{eV}$ & $\mathrm{Ag}^{\delta+} / \mathrm{O}$ & $\mathrm{VB} / \mathrm{eV}$ \\
\hline $\mathrm{O} \alpha_{1}$ & $528.1-528.4$ & $0.85-1.0$ & 4.7 & 2.1 \\
$\mathrm{O} \alpha_{2}$ & $529.1-529.2$ & $0.9-1.1$ & 2.3 & - \\
$\mathrm{O} \gamma$ & $529.5-529.7$ & $1.0-1.1$ & 0.9 & 2.6 \\
$\mathrm{O} \alpha_{3}$ & $530.1-530.4$ & $1.0-1.1$ & 0.2 & 3.0 \\
$\mathrm{O} \beta$ & $530.8-531.0$ & $1.1-1.2$ & 0.2 & 3.3
\end{tabular}

${ }^{a}$ Smaller FWHM are observed for single crystals while larger values are related to powders or foils at higher temperatures.

The $\mathrm{O} \alpha_{1}$ characterized by the lowest binding energy was already extensively investigated in the past ${ }^{11,32,38,39}$ and it is usually associated to the formation of oxygen induced reconstructions on different facets of Ag single crystals observed by low energy electron diffraction, ${ }^{7,38}$ and more recently surface X-ray diffraction. ${ }^{51,52}$ The exact atomic structure of these reconstructions is still focus of debate, ${ }^{53,54}$ but the correlation with the low BE feature observed by XPS seems to be consensual. Considerable variations of the $\mathrm{BE}$ values for this species can be observed in the literature, from 528.1 to $528.5 \mathrm{eV}$, for different single crystal facets and polycrystalline foil. In our measurements, using the same energy calibration, changes in the $\mathrm{BE}$ for $\mathrm{O} \alpha_{1}$ were observed not only for different Ag materials, but also for the same sample measured at different positions or times. These variations are larger than the accuracy of our energy calibration $(30 \mathrm{meV})$ and can be associated to the presence of regions with different reconstructions within the area illuminated by the incident X-rays (approximately $0.015 \mathrm{~mm}^{2}$ ). As recently demonstrated by Schnadt et al..$^{53}$ by a combination of STM images and theory, multiple surface structures are expected to coexist on silver surfaces exposed to oxygen at catalytic relevant temperatures, as a consequence of their small energy differences compared to the thermal energy. This coexistence of different phases could also explain the observed variations in the FWHM. Among all species, $\mathrm{O} \alpha_{1}$ was found to be related to the highest amount of $\mathrm{Ag}^{\delta+}$, confirming its oxidic nature as already pointed out by many authors. The relatively flat feature around $2.0 \mathrm{eV}$ in the VB spectrum agrees well with UPS ${ }^{10,32}$ and XPS ${ }^{38,55}$ spectra reported by other authors for $\mathrm{O}$ species with the same 
core-level BE. The disappearance of $\mathrm{O} \alpha_{1}$ at high temperatures (Fig. 2(a)) is an additional evidence for the association of this species with ordered structures on the surface.

The $\mathrm{O} \alpha_{2}$ species was also related to formation of $\mathrm{Ag}^{\delta+}$, but at a less extent than $\mathrm{O} \alpha_{1}$ providing it a weaker oxidic character. Based solely on the $\mathrm{BE}$ and the ionic character, this feature could be assigned as the $\mathrm{O} \gamma$ species following the previous work of Bao et al. However the kinetics and thermal stability are not consistent with this assignment. From the data at $150-230{ }^{\circ} \mathrm{C}$ (Fig. 1), it is clearly seen that $\mathrm{O} \alpha_{2}$ is present after few minutes of exposure to $\mathrm{O}_{2}$ at $150{ }^{\circ} \mathrm{C}$. TDS experiments for $\mathrm{Ag}$ exposed to $\mathrm{O}_{2}$ at temperatures lower than $300{ }^{\circ} \mathrm{C}$ do not show the high temperature desorption peak characteristic of $\mathrm{O} \gamma \cdot{ }^{27}$ Besides, the $\mathrm{Ag}$ foil exposed to oxygen at $500{ }^{\circ} \mathrm{C}$ for $12 \mathrm{~h}$ (Fig. 2) shows a broader peak with a higher binding energy relative to the $\mathrm{O} \alpha_{2}$ component at $150{ }^{\circ} \mathrm{C}$ and this feature shifts even further when $\mathrm{O}_{2}$ is removed, confirming that the highly stable $\mathrm{O} \gamma$ should be in fact assigned to the new component at $529.6 \mathrm{eV}$ instead. Features in the same range as $\mathrm{O} \alpha_{2}$ are reported in the literature even for low $\mathrm{O}_{2}$ exposures at low temperature, where formation of the so-called $\mathrm{O} \gamma$ is not expected. Rocca et $_{\text {al }}{ }^{38}$ reported that oxygen species at $528.3 \mathrm{eV}\left(\mathrm{O} \alpha_{1}\right)$ created on $\mathrm{Ag}(001)$ by low $\mathrm{O}_{2}$ doses at room temperature can be totally removed by $\mathrm{CO}$ exposure resulting in a residual peak in the same range as $\mathrm{O} \alpha_{2}$. This peak was interpreted as oxide-like species at steps on $\mathrm{Ag}(001)$. This proposition is well aligned with our observations. $\mathrm{O} \alpha_{2}$ is not immediately formed after the temperature is raised to $150{ }^{\circ} \mathrm{C}$, but it appears only after some time, probably when more steps and edges are created at the surface. Also, the amount of $\mathrm{O} \alpha_{2}$ relative to $\mathrm{O} \alpha_{1}$ seems to be higher for powders than for single crystals, for which a higher density of defects is expected. Moreover, the total amount of $\mathrm{O} \alpha_{2}$ on the Ag foil increased by a factor of two when the temperature was increased from $180{ }^{\circ} \mathrm{C}$ to $500{ }^{\circ} \mathrm{C}$ (Fig. 2(b)) along with strong morphological changes that resulted in the micrometre sized facets and steps observed by SEM (Fig. 4). Recently, Su et al. ${ }^{56}$ found indications for the presence of oxygen species on the steps at the surface of Ag nanoparticles exposed to air, without any high temperature treatments, by a combination of aberration corrected HRTEM images associated to DFT calculations and image simulation.

We found that the highly stable oxygen species $\mathrm{O} \gamma$ was related to less $\mathrm{Ag}^{\delta+}$ than both $\mathrm{O} \alpha_{1}$ and $\mathrm{O} \alpha_{2}$, although the dataset is scarcer, which is in contrast to the description of $\mathrm{O} \gamma$ as an oxidic species in previous works of our group. ${ }^{25,26}$ This divergence can be related to the fact that species identification was simply based on the major features in the O1s spectra because of the limited resolution provided by lab source XPS, which most likely precluded the distinction between $\mathrm{O} \gamma$ and the $\mathrm{O} \alpha_{2}$. This argument is corroborated by the presence of a VB feature at $2.6 \mathrm{eV}$ for the case of a mixture of $\mathrm{O} \gamma$ and the $\mathrm{O} \alpha_{2}$ in the $\mathrm{Ag}$ foil (Fig. 8), which agrees with a peak at $2.5 \mathrm{eV}$ associated to $\mathrm{O} \gamma$ in UPS measurements reported in previous works. $^{24}$

The identification of oxygen species on silver in the range of 530-531 was the focus of debate in the literature. Initial skepticism was related to the possibility that these features might be related to carbonates and not adsorbed oxygen on silver. ${ }^{37} \mathrm{Few}$ authors assigned features around $530 \mathrm{eV}$ to molecularly adsorbed oxygen, ${ }^{57,58}$ however the atomic nature of oxygen species at temperatures relevant for ethylene epoxidation was confirmed by Bukhtiyarov et al. using a combination of XPS and XAS measurements. ${ }^{59}$ Assignment as subsurface species was also proposed based on the dependence of the peak BE on its intensity, shifting from 530 to $531 \mathrm{eV}$ and the considerably bigger broadening compared to low $\mathrm{BE}$ species observed for the same sample. ${ }^{26}$ On the other hand, the surface location of species with $\mathrm{BE} 530.3 \mathrm{eV}$ was evidenced by XPD for the case of $\mathrm{Ag}(001)$ single crystals exposed to low $\mathrm{O}_{2}$ doses below room temperature ${ }^{38}$ and by angle dependent XPS for the case of $\operatorname{Ag}(111){ }^{60}$

In our case, measurements of photoelectrons with the same kinetic energy, which provides more comparable sensitivity factors for $\mathrm{O} 1 \mathrm{~s}$ and $\mathrm{C} 1 \mathrm{~s}$, allows us to safely exclude the presence of carbonates. Moreover, our analysis indicates the separation of the O1s features at $530-531 \mathrm{eV}$ into two distinct species, $\mathrm{O} \alpha_{3}$ at $530.2-530.6$ and $\mathrm{O} \beta$ at $530.8-531 \mathrm{eV}$ (see ESI $\dagger$, Fig. S2). The $\mathrm{O} \alpha_{3}$ component can be unequivocally related to the so-called electrophilic oxygen reported in the papers of Buhktyiarov et al., ${ }^{32,59,60}$ based on the BE position, absence of induced $\mathrm{Ag}^{\delta+}$ for this species and the VB feature around $3.1 \mathrm{eV}$. The identification of the higher BE component at $530.8 \mathrm{eV}$ as $\mathrm{O} \beta$ species located below the silver surface is confirmed by various hints obtained by a careful examination of our dataset in comparison with the literature.

First, oxygen migration to the subsurface region was proposed to be driven by lateral repulsion of surface species at higher coverages and by the increased solubility in silver as the temperature is raised. ${ }^{61}$ This scheme is in agreement with our observation of a delayed formation of $\mathrm{O} \beta$ at $180{ }^{\circ} \mathrm{C}$ relative to the surface species $\mathrm{O} \alpha_{1}$ (Fig. 2(b)) and its relative increase with temperature for the $\operatorname{Ag}(110)$ (Fig. 2(a)). Likewise, the higher amount of $\mathrm{O} \beta$ (relative to $\mathrm{O} \alpha_{1}$ ) for the powder in comparison to $\operatorname{Ag}(110)$ is a further indication, given that the higher density of defects and grain boundaries in powders is expected to enhance the oxygen incorporation in the subsurface. Second, the kinetics at $500{ }^{\circ} \mathrm{C}$ also supports this assignment. It was observed that $\mathrm{O} \beta$ is formed at intermediate stages before $\mathrm{O} \gamma$ appears (Fig. 3(a and b)), which is in full agreement with a previous model derived from TPD and ISS that identifies $\mathrm{O} \beta$ as a precursor for $\mathrm{O} \gamma \cdot{ }^{26} \mathrm{It}$ is worth mentioning that the ratio of $\mathrm{O} \beta / \mathrm{O} \gamma$ in our present work is considerably lower than previously reported XPS data, ${ }^{25}$ however this is in agreement with the TPD experiments performed by Nagy et al. ${ }^{27}$ for $\mathrm{Ag}$ foils exposed to $\mathrm{O}_{2}$ at different pressures showing a relative decrease of the $\mathrm{O} \beta / \mathrm{O} \gamma$ desorption peak intensity ratio as the pressure was reduced from 1 bar to 10 mbar. Thirdly, the VB shoulder at $3.3 \mathrm{eV}$ (Fig. 6) is consistent with this assignment as $\mathrm{O} \beta$, being comparable to a feature at $3.2 \mathrm{eV}$ observed by UPS on Ag foil after treatments for which $\mathrm{O} \beta$ is expected..$^{25}$ Finally, comparison of the experimentally determined $\mathrm{O} / \mathrm{Ag}$ atomic concentration ratios for $\mathrm{O} \beta$ with numerical calculations (presented in ESI $\dagger$ ) suggests that the measured amounts of $\mathrm{O} \beta$ are considerably higher than what is expected for an $\mathrm{O}$ overlayer with $1 \mathrm{ML}$ coverage on atomically flat $\operatorname{Ag}(111)$, which corroborate the argument that this species might extend below the surface into the sub-surface and bulk regions. 
The dynamic nature of the interaction of oxygen with silver at elevated temperatures was established in the past in a series of papers ${ }^{17-27}$ combining different experimental techniques. In this context, oxygen migration to the sub-surface/bulk by interstitial diffusion played a central role as a driving force for the solid state dynamics that results in the surface restructuring and also as a precursor for the formation of highly stable oxygen species. In the present paper, this model is corroborated by the observation of similar dynamic behavior using an in situ surface sensitive technique for the case of silver samples in constant interaction with gas phase $\mathrm{O}_{2}$. The $\mathrm{O} \beta$ accumulation and posterior formation of $\mathrm{O} \gamma$ with simultaneous surface morphological changes observed for the silver foil exposed to $500{ }^{\circ} \mathrm{C}$ is in an excellent agreement with the high pressure experiments. Also, since the experiments were performed under equilibrium conditions, the association of these dynamic transformations to transient states created during the thermal desorption experiments can be safely ruled out.

In addition our results indicate that oxygen incorporation to the subsurface is also present at relatively lower temperatures typical of ethylene epoxidation. The clear dependence on time and temperature for $\mathrm{O} \beta$ accumulation at $180{ }^{\circ} \mathrm{C}$ suggests that oxygen diffusion is a thermally activated kinetic process in agreement with the high temperature results. The presence of sub-surface oxygen might be related to the formation of the $\mathrm{O} \alpha_{3}$ species with electrophilic character and identified as responsible for the ethylene oxide formation. ${ }^{33}$ Rocca and co-workers ${ }^{38}$ reported a reversible transformation of oxygen species at $530.3 \mathrm{eV}$ and $528.3 \mathrm{eV}$ on $\mathrm{Ag}(001)$ upon heating from $150 \mathrm{~K}$ to $300 \mathrm{~K}$ and proposed that the transition arises from the depletion of oxygen at subsurface sites leading to a destabilization of the species at $530.3 \mathrm{eV}$ as the temperature is increased, but subsurface species were not identified. Van Santen and Kuipers ${ }^{62}$ also proposed a mechanism whereby the presence of subsurface oxygen renders the surface adsorbed oxygen more electrophilic by withdrawing electron density from its surroundings. These arguments are in agreement with our observation of lack of $\mathrm{Ag}^{\delta+}$ and higher $\mathrm{BE}$ for $\mathrm{O} \alpha_{3}$ relative to $\mathrm{O} \alpha_{1}$ and $\mathrm{O} \alpha_{2}$.

Based on these observations, a common framework for the description of oxygen species on silver can be constructed contemplating both the static description of oxygen species in the surface science literature at low temperature/pressure and the dynamics revealed at high pressure/temperature. At low oxygen chemical potential, dissociative adsorption of oxygen at the silver creates the $\mathrm{O} \alpha_{1}$ species related to the surface reconstructions observed in many low oxygen dose studies. As the oxygen chemical potential is slightly increased, either by higher doses or temperatures, $O \beta$ starts to be formed by slow migration of adsorbed oxygen to sites below the Ag surface. The presence of oxygen in the subsurface then polarizes the $\mathrm{Ag}-\mathrm{O}$ bond for the surface oxygen species creating the $\mathrm{O} \alpha_{3}$ species. At even higher oxygen chemical potentials, under methanol oxidation reaction temperatures, oxygen interstitial diffusion to the bulk is strongly enhanced and the silver undergoes strong structural and morphological changes resulting in the surface faceting that favors the $\mathrm{O} \alpha_{2}$ species and the formation of $\mathrm{O} \gamma$ by migration of oxygen to vacancies in the silver lattice. In this scenario, a key element is the presence of oxygen in the subsurface/bulk driven by the oxygen chemical potential.
The kinetics of $O \beta$ formation at different temperatures and its relationship with $\mathrm{O} \alpha_{3}$ are being further investigated and will be presented in a forthcoming publication.

\section{Conclusions}

In summary we find that under constant oxygen chemical potential provided by mbar range pressure and catalytically relevant temperatures the silver-oxygen system shows a dynamic behavior that can be captured by near ambient pressure XPS. Our data show that silver is able to activate molecular oxygen into different forms with clearly distinct characteristics that might relate to different roles in both methanol and ethylene epoxidation reactions. This formation of different oxygen species on silver is interpreted as a result of oxygen incorporation below the surface that changes the atomic and electronic structure of the metal. It is expected that the strong evidence presented here, based on a set of independent measurements, will help to shed new light in the mechanism of oxygen activation that can be used to further understand the oxidation reactions performed on silver catalysts.

\section{Acknowledgements}

We thank the Helmholtz-Zentrum Berlin for providing longtime support of the high pressure electron spectroscopy activities of the FHI at BESSY II.

\section{Notes and references}

1 B. K. Hodnett and B. K. Hodnett, Heterogeneous catalytic oxidation: fundamental and technological aspects of the selective and total oxidation of organic compounds, John Wiley, 2000.

2 Handbook of Heterogeneous Catalysis, ed. G. Ertl, H. Knözinger, F. Schüth and J. Weitkamp, Wiley-VCH Verlag GmbH \& Co. KGaA, Weinheim, Germany, 2008.

3 A. W. Czanderna, J. Phys. Chem., 1964, 68, 2765-2771.

4 A. W. Czanderna, Thin Solid Films, 1972, 12, S21-S24.

5 P. G. Hall and D. A. King, Surf. Sci., 1973, 36, 810-812.

6 A. W. Czanderna, J. Vac. Sci. Technol., 1977, 14, 408.

7 G. Rovida, F. Pratesi, M. Maglietta and E. Ferroni, Surf. Sci., 1974, 43, 230-256.

8 C. Backx, C. P. M. De Groot and P. Biloen, Surf. Sci., 1981, 104, 300-317.

9 G. G. Tibbetts and J. M. Burkstrand, Phys. Rev. B: Condens. Matter Mater. Phys., 1977, 16, 1536.

10 K. C. Prince and A. M. Bradshaw, Surf. Sci., 1983, 126, $49-57$.

11 R. W. Joyner and M. W. Roberts, Chem. Phys. Lett., 1979, 60, 459-462.

12 C.-T. Au, S. Singh-Boparai, M. W. Roberts and R. W. Joyner, J. Chem. Soc., Faraday Trans. 1, 1983, 79, 1779-1791.

13 X. Liu, R. J. Madix and C. M. Friend, Chem. Soc. Rev., 2008, 37, 2243.

14 W. M. H. Sachtler, C. Backx and R. A. Van Santen, Catal. Rev.. Sci. Eng., 1981, 23, 127.

15 R. A. van Santen and C. P. M. de Groot, J. Catal., 1986, 98, 530-539.

16 I. E. Wachs and R. J. Madix, Surf. Sci., 1978, 76, 531-558.

17 C. Rehren, G. Isaac, R. Schlögl and G. Ertl, Catal. Lett., 1991, 11, 253-265.

18 C. Rehren, M. Muhler, X. Bao, R. Schlögl and G. Ertl, Z. Phys. Chem., 1991, 174, 11-52.

19 X. Bao, G. Lehmpfuhl, G. Weinberg, R. Schlogl and G. Ertl, Faraday Trans., 1992, 88, 865-872.

20 X. Bao, M. Muhler, B. Pettinger, R. Schlögl and G. Ertl, Catal. Lett., 1993, 22, 215-225.

21 X. Bao, J. V. Barth, G. Lehmpfuhl, R. Schuster, Y. Uchida, R. Schlögl and G. Ertl, Surf. Sci., 1993, 284, 14-22. 
22 H. Schubert, U. Tegtmeyer and R. Schlögl, Catal. Lett., 1994, 28, 383-395.

23 H. Schubert, U. Tegtmeyer, D. Herein, X. Bao, M. Muhler and R. Schlögl, Catal. Lett., 1995, 33, 305-319.

24 X. Bao, M. Muhler, B. Pettinger, Y. Uchida, G. Lehmpfuhl, R. Schlögl and G. Ertl, Catal. Lett., 1995, 32, 171-183.

25 X. Bao, M. Muhler, T. Schedel-Niedrig and R. Schlögl, Phys. Rev. B: Condens. Matter Mater. Phys., 1996, 54, 2249.

26 T. Schedel-Niedrig, R. Schlögl, X. Bao and M. Muhler, Ber. Bunsenges. Phys. Chem., 1997, 101, 994-1006.

27 A. J. Nagy, G. Mestl, D. Herein, G. Weinberg, E. Kitzelmann and R. Schlögl, J. Catal., 1999, 182, 417-429.

28 W.-X. Li, C. Stampfl and M. Scheffler, Phys. Rev. B: Condens. Matter Mater. Phys., 2002, 65, 075407.

29 W.-X. Li, C. Stampfl and M. Scheffler, Phys. Rev. B: Condens. Matter Mater. Phys., 2003, 68, 165412.

30 W.-X. Li, C. Stampfl and M. Scheffler, Phys. Rev. B: Condens. Matter Mater. Phys., 2003, 67, 045408.

31 W.-X. Li, C. Stampfl and M. Scheffler, Phys. Rev. Lett., 2003, 90, 256102 .

32 V. I. Bukhtiyarov, M. Hävecker, V. V. Kaichev, A. Knop-Gericke, R. W. Mayer and R. Schlögl, Phys. Rev. B: Condens. Matter Mater. Phys., 2003, 67, 235422.

33 V. I. Bukhtiyarov, A. I. Nizovskii, H. Bluhm, M. Hävecker, E. Kleimenov, A. Knop-Gericke and R. Schlögl, J. Catal., 2006, 238, 260-269.

34 H. Bluhm, M. Havecker, A. Knop-Gericke, M. Kiskinova, R. Schlogl and M. Salmeron, MRS Bull., 2007, 32, 1022-1030.

35 A. Knop-Gericke, E. Kleimenov, M. Hävecker, R. Blume, D. Teschner, S. Zafeiratos, R. Schlögl, V. I. Bukhtiyarov, V. V. Kaichev, I. P. Prosvirin, A. I. Nizovskii, H. Bluhm, A. Barinov, P. Dudin and M. Kiskinova, Adv. Catal., 2009, 52, 213-272.

36 J. J. Yeh and I. Lindau, At. Data Nucl. Data Tables, 1985, 32, $1-155$.

37 C. T. Campbell, Surf. Sci., 1985, 157, 43-60.

38 M. Rocca, L. Savio, L. Vattuone, U. Burghaus, V. Palomba, N. Novelli, F. Buatier de Mongeot, U. Valbusa, R. Gunnella, G. Comelli, A. Baraldi, S. Lizzit and G. Paolucci, Phys. Rev. B: Condens. Matter Mater. Phys., 2000, 61, 213.

39 C. T. Campbell and M. T. Paffett, Surf. Sci., 1984, 143, 517-535.

40 A. I. Boronin, S. V. Koscheev, K. T. Murzakhmetov, V. I. Avdeev and G. M. Zhidomirov, Appl. Surf. Sci., 2000, 165, 9-14.

41 L. S. Kibis, V. I. Avdeev, S. V. Koscheev and A. I. Boronin, Surf. Sci., 2010, 604, 1185-1192.
42 G. Rupprechter, H. Unterhalt, M. Morkel, P. Galletto, L. Hu and H.-J. Freund, Surf. Sci., 2002, 502-503, 109-122.

43 D. Y. Zemlyanov, E. Savinova, A. Scheybal, K. Doblhofer and R. Schlögl, Surf. Sci., 1998, 418, 441-456.

44 A. Klust and R. J. Madix, Surf. Sci., 2006, 600, 5025-5040.

45 D. Briggs and J. T. Grant, Surface Analysis by Auger and X-Ray Photoelectron Spectroscopy, IM Publications, 2003.

46 N. V. Smith, G. K. Wertheim, S. Hüfner and M.M. Traum, Phys. Rev. B: Condens. Matter Mater. Phys., 1974, 10, 3197.

47 L. H. Tjeng, M. B. J. Meinders, J. van Elp, J. Ghijsen, G. A. Sawatzky and R. L. Johnson, Phys. Rev. B: Condens. Matter Mater. Phys., 1990, 41, 3190.

48 M. T. Czyyk, R. A. de Groot, G. Dalba, P. Fornasini, A. Kisiel, F. Rocca and E. Burattini, Phys. Rev. B: Condens. Matter Mater. Phys., 1989, 39, 9831.

49 F. M. F. de Groot, M. Grioni, J. C. Fuggle, J. Ghijsen, G. A. Sawatzky and H. Petersen, Phys. Rev. B: Condens. Matter Mater. Phys., 1989, 40, 5715.

50 P. Behrens, Solid State Commun., 1992, 81, 235-239.

51 M. Schmid, A. Reicho, A. Stierle, I. Costina, J. Klikovits, P. Kostelnik, O. Dubay, G. Kresse, J. Gustafson, E. Lundgren, J. N. Andersen, H. Dosch and P. Varga, Phys. Rev. Lett., 2006, 96, $146102-4$.

52 A. Stierle, I. Costina, S. Kumaragurubaran and H. Dosch, J. Phys. Chem. C, 2007, 111, 10998-11002.

53 J. Schnadt, J. Knudsen, X. L. Hu, A. Michaelides, R. T. Vang, K. Reuter, Z. Li, E. Lægsgaard, M. Scheffler and F. Besenbacher, Phys. Rev. B: Condens. Matter Mater. Phys., 2009, 80, 075424.

54 A. Michaelides, K. Reuter and M. Scheffler, J. Vac. Sci. Technol., A, 2005, 23, 1487-1497.

55 L. H. Tjeng, M. B. J. Meinders and G. A. Sawatzky, Surf. Sci., 1990, 236, 341-368

56 D. S. Su, T. Jacob, T. W. Hansen, D. Wang, R. Schlögl, B. Freitag and S. Kujawa, Angew. Chem., Int. Ed., 2008, 47, 5005-5008.

57 A. I. Boronin, S. V. Koscheev, V. F. Malakhov and G. M. Zhidomirov, Catal. Lett., 1997, 47, 111-117.

58 A. Boronin, S. Koscheev and G. Zhidomirov, J. Electron Spectrosc. Relat. Phenom., 1998, 96, 43-51.

59 V. I. Bukhtiyarov, M. Hävecker, V. V. Kaichev, A. Knop-Gericke, R. W. Mayer and R. Schlögl, Catal. Lett., 2001, 74, 121-125.

60 V. I. Bukhtiyarov, V. V. Kaichev and I. P. Prosvirin, J. Chem. Phys., 1999, 111, 2169-2175.

61 A. Bielanski and J. Haber, Oxygen in catalysis, Marcel Dekker, NY, 1991

62 R. Van Santen and H. Kuipers, Adv. Catal., 1987, 35, 265-321. 